\title{
Orthurus heterocarpus (Boiss.) Juz. Bitkisinin Kökleri Üzerinde Farmakognozik Araştırmalar*
}

\author{
Pharmacognosic Researches on the Roots of Orthurus \\ heterocarpus (Boiss.) Juz.
}

Nevin TANKER Bilge ŞENER**

Memleketimizin özellikle güney Anadolu bölgesinde yaygın olarak bulunan Orthurus heterocarpus (Boiss.) Juz., bitkisi halk arasında "karanfil", "karanfil kökü" gibi isimlerle bilinmekte ve bu bitkinin toprakaltı kısımları kurutulduktan sonra hem hoş bir koku vermek üzere, az miktarda çaya katılmakta hem de çay gibi kaynatılarak mide ağrılarına ve diyareye karşı kullanılmaktadır.

Bitkinin kökleri, kurumakla artan, belirgin öjenol kokusu taşımaktadır. Kokunun gerçekten öjenole ait olduğu ön denemelerle saptandıktan sonra bitkinin bu açıdan değerlendirilmesi düşünüldü.

Antiseptik ve analjezik bir madde olan öjenol, tropiklerde yetişen Eugenia caryophyllata Thunb. (= Jambosa caryophyllus Niedenzu.) (Myrtaceae) bitkisinin çiçek tomurcuklarından subuharı distilasyonu ile elde edilen karanfil yağında fazla miktarda bulunmaktadır.

Öjenol, diş hekimliğinde çinko oksit ile pat halinde kullanıldıktan başka, analjezik etkisi nedeniyle doğrudan doğruya bir pamuğa emdirilerek, açılan kanala konulmak suretiyle de uygulanmaktadır. Bunlardan başka, geniş kullanılma alanı olan, vanilin'in sentezinde, başlangıç maddesi olarak ta öjenolden yararlanılmaktadır.

Redaksiyona verildiği tarih: 19 Nisan 1977

* Ecz. Bilge Şener'in "Orthurus heterocarpus (Boiss.) Juz. Bitkisinin Kökleri Üzerinde Farmakognozik Araştırmalar" isimli Doktora Tezinin Botanik Kısmının özetidir. Sınav tarihi: Şubat 1977.

** Farmakognozi ve Farmasötik Botanik Kürsüsü, Eczacılık Fakültesi, Ankara Üniversitesi. 
Türkiye'nin ithal ettiği başlıca ilâç hammaddelerinden biri olan öjenol, ortalama, yılda 2-3 ton kadar tüketilmektedir*.

E. caryophylatta memleketimizde yetişmediğine göre, ilâç endüstrimize hammadde sağlamak yönünden katkıda bulunacak ve aynı amaçlarla kullanılacak başka bitki ve kaynaklar aranmalıydı.

$\mathrm{Bu}$ açıdan hareketle, memleketimizde yaygın olarak bulunan Orthurus heterocarpus'un toprakaltı kısımlarından elde edilecek uçucu yağın, ithal edilen karanfil yağı yerine, diş hekimliğinde kullanılıp kullanılamayacağını saptamak üzere, bitkinin toprakaltı kısımları ve özellikle uçucu yağı üzerinde çalışmayı amaçladık.

Esas çalışma bu bitki üzerinde olmakla beraber, memleketimizde yetişen ve güney Avrupa'da "karanfil kökü" adı altında eczacılıkta kullanılmış olan (5), bir tür, Geum urbanum L. da incelenerek karşılaştırmalı bir çalışma sürdürüldü.

Önce bitkiyi ve toprakaltı kısımlarını tanımaya yarayacak morfolojik ve anatomik özelikler saptandı. Bundan sonra, toprakaltı kısımlarının içerdiği maddeler belirlenip, miktarları tayin edildikten başka, uçucu yağın bileşimi, değişik yöntemlerle aydınlatıldı ve sonuçlar karşılaştırıldı.

\section{MAT E R Y A L}

Antalya'nın Elmalı ilçesine bağlı bulunan Çı̆̆lıkara yöresinde, 1790-2300 m yükseklerde, sedir ağaçlarının altında, kireçli kayalar ve çalılar arasında tek ya da kümeler halinde rastlanan $O$. heterocarpus bitkisi, 1975 mayıs, ağustos ve 1976 mayıs aylarında toplandı. Bitki mayıs ayında çiçekli, ağustosta ise meyvalı olarak bulunmaktatadir.

Morfolojik ve anatomik incelemeler için ayrılan çiçek, yaprak, kök ve rizom örnekleri, $70^{\circ}$ lik etanol içine alınarak saklandı. Ayrıca nemli bez arasında taze olarak Ankara'ya getirdiğimiz kök ve rizomlar, A. Ü. Ecz. Fak. Tıbbî ve Zehirli Bitkiler bahçesine dikildi.

Karşılaştırma yapmak üzere $G$. urbanum'u da 1976 haziran ayında ve çiçekli iken, Ankara-Kırşehir yolu üzerindeki Beynam ormanından (1130 m yükseklikte) topladık.

* Yılık Dış Ticaret İstatistikleri. 
DAVIS e göre, Rosaceae familyasının Dryadeae alt familyasına özgü özelikleri taşıyan ve birbirine çok benzeyen Orthurus (Boiss.) Juz. ve Geum L. cinsleri stilusun şekli, a ke n le ri n say -

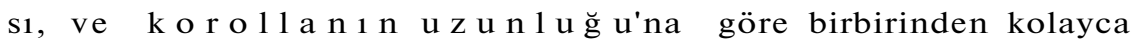
ayırdedilebilmektedir. Orthurus cinsinde stilus düz, korolla kaliksten kısa ve meyva 5-15 akenlidir. Geum cinsinde ise, stilus tepede çengel gibi kıvrık, korolla kaliksten uzundur ve meyva 50-250 akenden oluşmuştur(3).

Orthurus heterocarpus (Boiss.) Juz.; Geum heterocarpum Boiss., G. umbrosum Boiss. , ve G. micropetalum Gasparini isimleriyle de bilinmektedir $(1,2)$. Orthurus cinsinin bugüne kadar tek bir türüne rastlanmıştır.

Bitki batı, güney ve iç Anadoluda yaygındır. 1030-2300 m yüksekliklerde, gölgeli, kireçtaşlı kayalar arasında, orman açıklıklarında çoğunlukla Juniperusların altında yetişir. Kütahya (Murat dağı). Konya (Taşkent, 1450-1550 m), Isparta (Çiçek dağı, 1600 m), Denizli (Honaz dağı), Antalya (Elmalı), İçel (Mut-Ermenek, $1800 \mathrm{~m}$ ), Adana (Bürücek, 1630 m), K. Maraş (Ahır dağı, 1630 m), Kayseri (Sarız'ın $5 \mathrm{~km}$ kuzeyi, $1900 \mathrm{~m}$ ), Sivas (Gürün-Pmarbaş1, $2300 \mathrm{~m}$ ), Erzincan (Kemaliye), Gaziantep'te (Kurt dağı, $1036 \mathrm{~m}$ ) rastlanmış$\operatorname{tir}(3)$.

\section{B U L G U L A R}

Morfolojik İnceleme:

Çalışmalarımızı yürüttüğümüz $O$. heterocarpus bitkisi, Antalya'nın Elmalı ilçesine bağlı bulunan Çı̆̆lıkara yöresindeki sedir ormanından toplanmıştır. Bitki $35-40 \mathrm{~cm}$ yüksekliğinde, sık yumuşak tüylü, yaprak sapları çoğunlukla dik olan, çok yıllık, rizomlu bir bitkidir. Toprak altında 0.5 - $1.0 \mathrm{~cm}$ çapında $2-6 \mathrm{~cm}$ boyunda, odunsu bir rizom taşır. Rizom, çürümüş yaprak sapı artıkları ve 1-3 mm çapında, $5-25 \mathrm{~cm}$ uzunluğunda, saçak şeklinde, rengi açıktan koyu kahverengine kadar değişen köklerle örtülmüştür, Rizom ve kökler karanfil kokulu olup, buruk lezzetlidir.

Gövde kısa (1.5 - $2 \mathrm{~cm}$ kadar), yuvarlak ve hafif tüylüdür.

Taban yaprakları lirat, 8-15 cm uzunluğunda, 4-5 $\mathrm{cm}$ eninde, sık tüylü ve uzun saplıdır (9-12 cm kadar). Uçta bulunan büyük lob 
3.5-5 cm kadar, kordat ya da reniform, trifid (bazan 5 parçalı), tepesi rotundat, kenarları krenat-serrat. Alttaki loblar 2 ya da 4 çift, tabana doğru daha küçük (şek. 1).

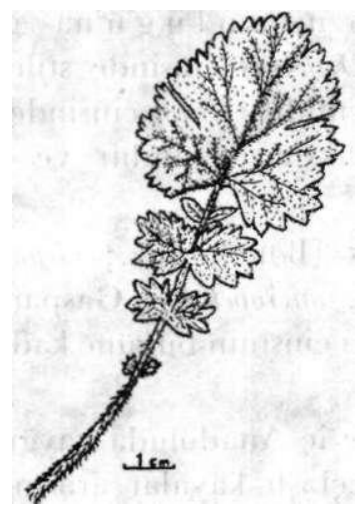

Şek, 1. Taban yapră̆ı

Gövdeden çıkan yapraklar sapsız, lirat, uçtaki lob orbikülar, trifid, tepesi rotundat ve kenarları krenat-serrattır (Şek. 2).

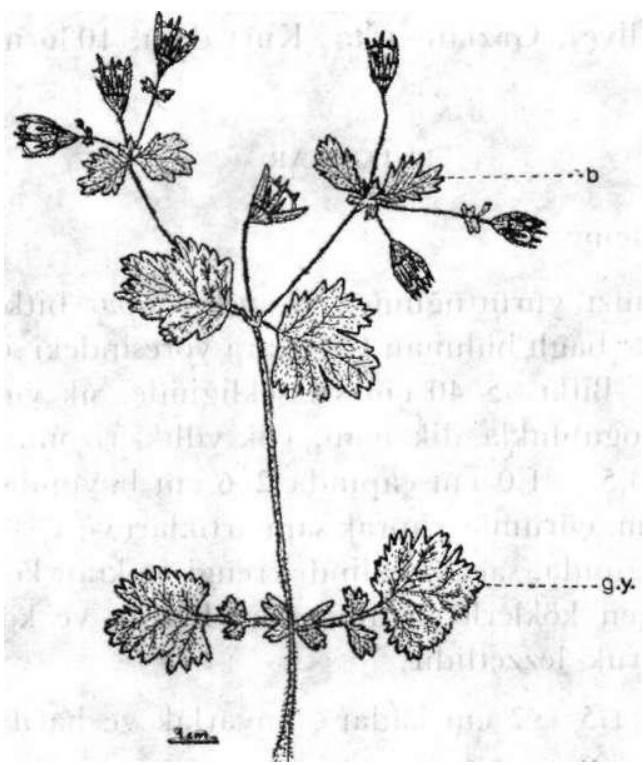

Şek. 2. O. heterocarpus'tan çiçekli bir dal, g. y. gövde yapraklan, b. brakte 
Çiçek durumu bileşik dikazyum biçiminde (Şek. 2), çoğunlukla

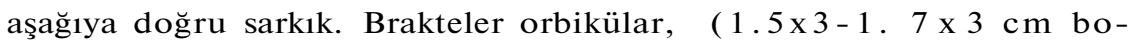
yutlarında), bazan oblong, trifid ve kenarları serrattır (Şek. 2).

Çiçekler, 1.5 -2 cm uzunluktaki bir sapın üzerinde, 1-2 cm büyüklükte, hermafrodit ve aktinomorftur (Şek. 3). Kaliks çan şeklinde, tabanda birleşik 5 parçalı, sepaller 13-15 mm uzunluk ve 1.5 - 2 $\mathrm{mm}$ genişlikte, lanseolat, tepesi akut, kenarları tam ve siliattir. Sepallerin arasında, 6-10 mm uzunluk ve 1-1.5 mm genişlikte, 5 tane linear epikaliks parçası bulunur (Şek. 3 a).

Korolla apopetal, 5 petalli; petaller beyazımsı sarı, sepallerden daha kısa, 7-8 mm uzunluk ve 5-6 $\mathrm{mm}$ genişlikte, obovat, tepesi obtus ve hafif dalgalı, tabanı kuneat (Şek. 3 c).

Stamenler çok sayıda ve korolladan kısa olup, sepallerin alt kısmına, koyu renkli bir halka boyunca bağlamıştır ve kaliks tübünü bir astar gibi sarar (Şek. 3 b). Filamentler uzunca, anterler versatil, sarı renkli ve ekstrorstur (Şek. $3 \mathrm{~d}$ ).

Ginekeum üst durumlu ve apokarptır. Ovaryum 2-3 mm uzunlukta, ovat-linear biçimde, stilus ovaryumdan uzun, eklemli, ovaryuma yakın bölümü ve ovaryumun üstü kısa tüylerle örtülü. Stigma sarı renkli ve tek parçalı (Şek. 3 e, f). Sayıları 8-11 arasında değişen pistliler, 2-2.5 $\mathrm{mm}$ boyundaki ginofor'a ve çiçek tablasına bağlanmıştır, yalnız bir pistil ginoforun dibine bağlı bulunmaktadır.

Pistiller gelişirken karpofor da gelişerek 9-13 $\mathrm{mm}$ uzunluğa erişir (Şek. $3 \mathrm{~g}$ ) ; 8 ya da 11 aken taşıyan agregat bir meyva oluşur.

Meyvayı oluşturan akenler $7 \mathrm{~mm}$ boyda ve 2-3 $\mathrm{mm}$ genişliktedir Stilusun uç eklemi stigma ile birlikte kopmuştur. Akenin stilus ile birlikte uzunluğu 15-20 mm kadardır. Meyvaya bağlı kalan artığın uç kısmı ile meyva tüylerle örtülüdür (Şek. 3 h).

Tohumlar $4 \mathrm{~mm}$ boyunda, $1 \mathrm{~mm}$ eninde ve oval olup, boyuna çizgicikli kahverengimsi - kırmızı bir testa ile örtülüdür (Şek. 31 ).

Güney Avrupa'da yetişen ve eczacılıkta yararlanılan bir tür olan G. urbalum, 50-70 cm yüksekliğinde bir bitkidir. Taban yaprakları lirat, $15-30 \mathrm{~cm}$ büyüklüğünde, gövde yaprakları ise p e n n a t ve üç parçalıdır. Petaller, sepallerden uzun ve koyu sarı renklidir. Akenlede stilusun ucu çengel gibi kıvrıktır (Şek. 3 i), sayısı 

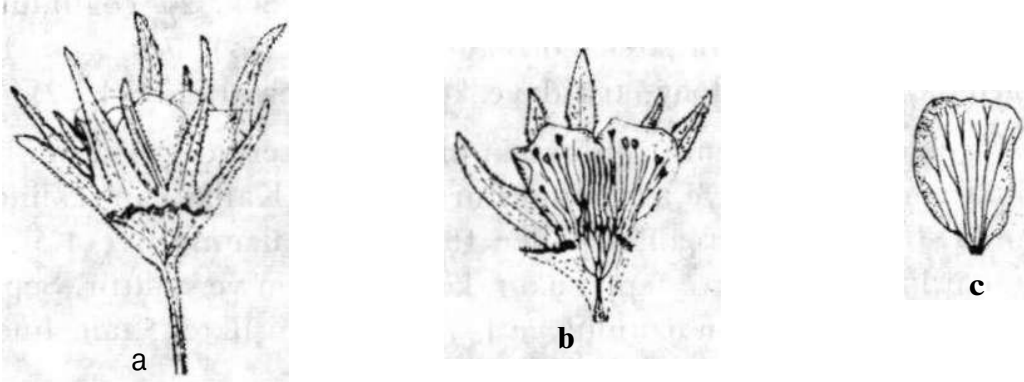

c

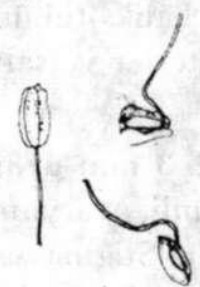

a

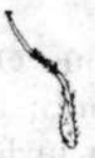

$\mathbf{e}$

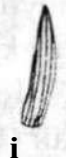

$1 \mathrm{~cm}$

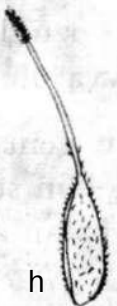

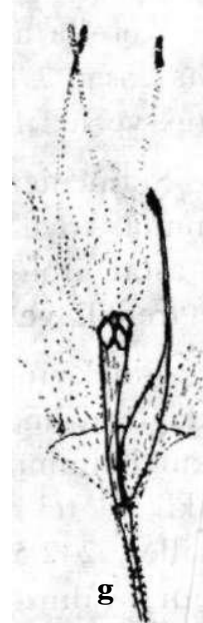
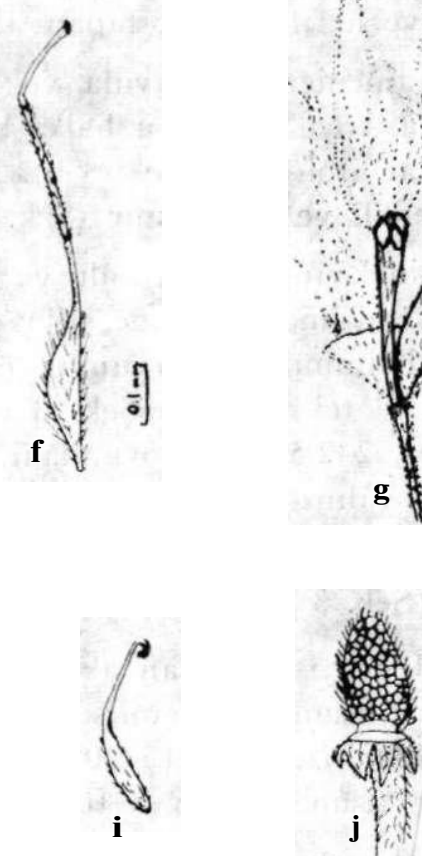

Şek. 3. O. heterocarpus'la çiçek ve meyva

a) kaliks ve epikaliks (dıştan görünüş), b) kaliks, korolla, androkeum ve girekeum (içten görünüş), c) tek bir petal, d) stamenler, e ve f) pistil, g) karpofor ve tıbana bağlı tek meyva, h) meyva, ı) tohum, i vej) G. urbanum'da bir aken ve reseptakulum 
50-100 kadar olup, üzeri tüylü ve koni biçimindeki bir reseptakulumun üzerinde toplanmıştır (Şek. $3 \mathrm{j}$ ). K a r p o f o r yoktur.

Anatomik inceleme:

Kök ve rizomlardan alınan enine kesiler, kloralhidrat çözeltisi ve Sartur reaktifi içinde incelendi.

Kök:

O. heterocarpus köklerinden alınan enine kesilerde (Şek. 4 a, b) mantar, kabuk ve merkezi silindir kolaylıkla görülmektedir.

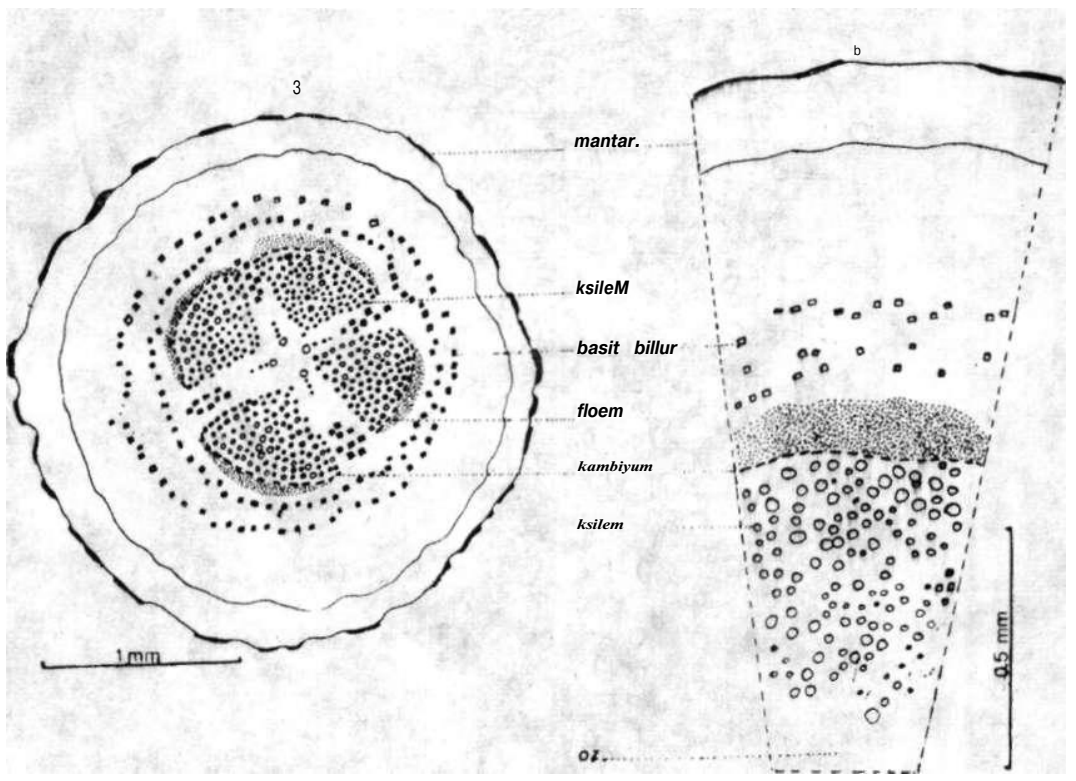

Şek. 4. Kökün enine kesiti, şematik

En dışta çeperi süberinleşmiş 5-6 sıra yassı hücre, altında, 8-10 sıra çeperi süberinleşmemiş ve hücreleri üsttekilere oranla daha büyük ve düzgün olan poliderm (4) bulunur. Poliderm tabakasının altında geniş bir kabuk bölgesi bulunmaktadır. Hücreleri az çok köşeli ve parenkimatiktir, bol miktarda uçucu yağ taşır. Sekonder floem dar bir şerit halindedir ve basit billur taşıyan hücrelerden oluşmuş bir halka ile çevrilmiştir. Kambiyum 2-3 sıralıdır. Sekonder ksilemde, trake ve trakeitlerin arasında, ince ve selülozik çeperli ksilem 
parenkiması hücreleri bulunur. Öz kolları 2-3 sıra hücre genişliğinde olup, basit billur taşır. Öz bölgesi, uçucu yağ damlaları taşıyan, izediyametrik, ince çeperli parenkima hücrelerinden oluşmuştur ve geniş değildir (Şek. 4, 5).

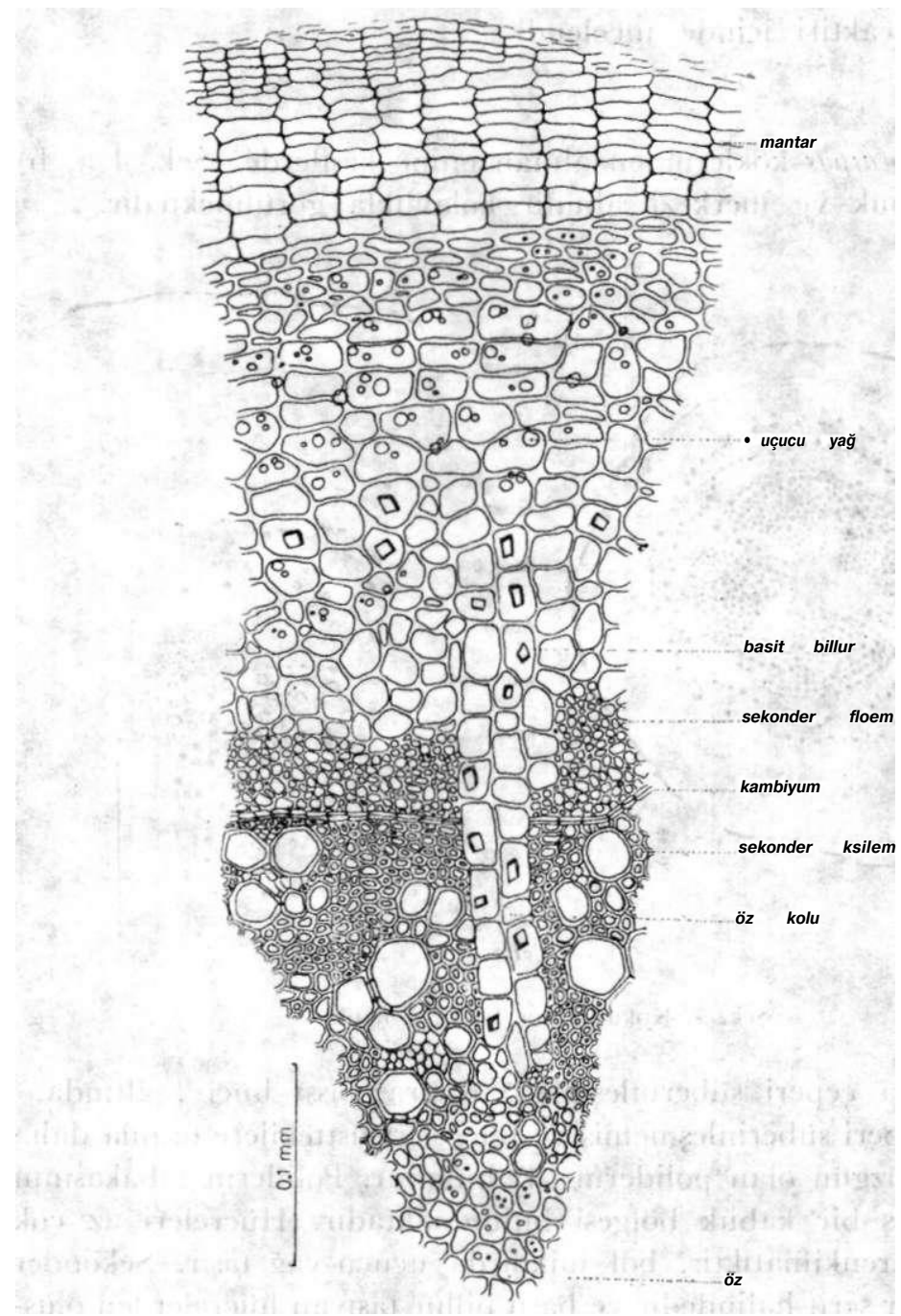

Şek. 5. Kökün enine kesiti, anatomik 
Rizom:

O. heterocarpus rizomlarından alınan enine keside (Şek. 6) geniş bir merkezi silindir ile nispeten dar bir kabuk parenkiması ve ekzoderma göze çarpar.

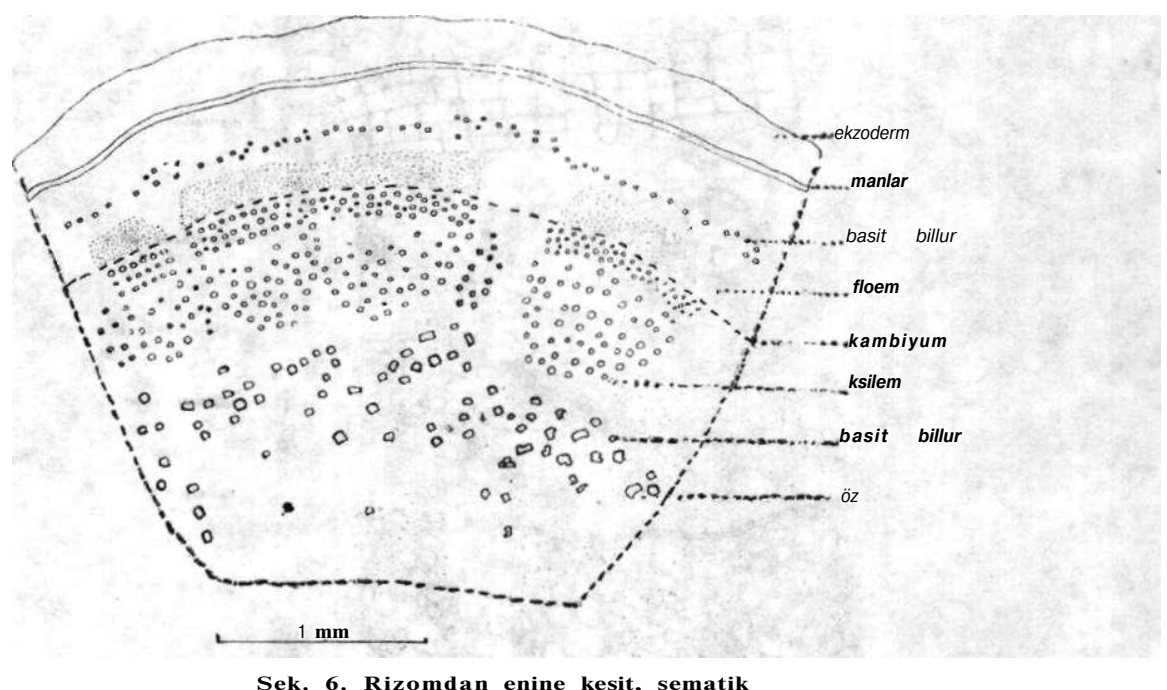

Sek. 6. Rizomdan enine kesit, sematik

En dışta, hücreleri izodiyametrik, büyük ve parçalanmış ekzoderm, bunun altında hücreleri küçük, çeperi süberinleşmiş, 4-5 sıralı mantar tabakası bulunur. Kabuk parenkiması ince çeperli hücrelerden oluşmuşur, yer yer sklerenkima demetlerine rastlanır. Parenkima hücrelerinin bazıları uçucu yağ taşır. Basit billurlar, kökte olduğu gibi, geniş bir yer kaplayan sekonder floemin etrafında bir halka biçiminde dizilmiştir. Kambiyum belirgin olup, 3-4 sıralıdır. Sekonder ksilemde yer alan trakeitler köktekilere oranla daha büyüktür. Öz kolları da, kökte olduğu gibi, basit billur taşır. Öz bölgesi oldukça geniş olup, büyük izodiyametrik parenkima hücrelerinden oluşmuştur. Bu parenkima hücrelerinde de uçucu yağ damlaları ve basit billur görülür. Basit billurların iki, üç, hatta dört tanesine, aynı hücre içinde rastlanabilmektedir (Şek. 7). 


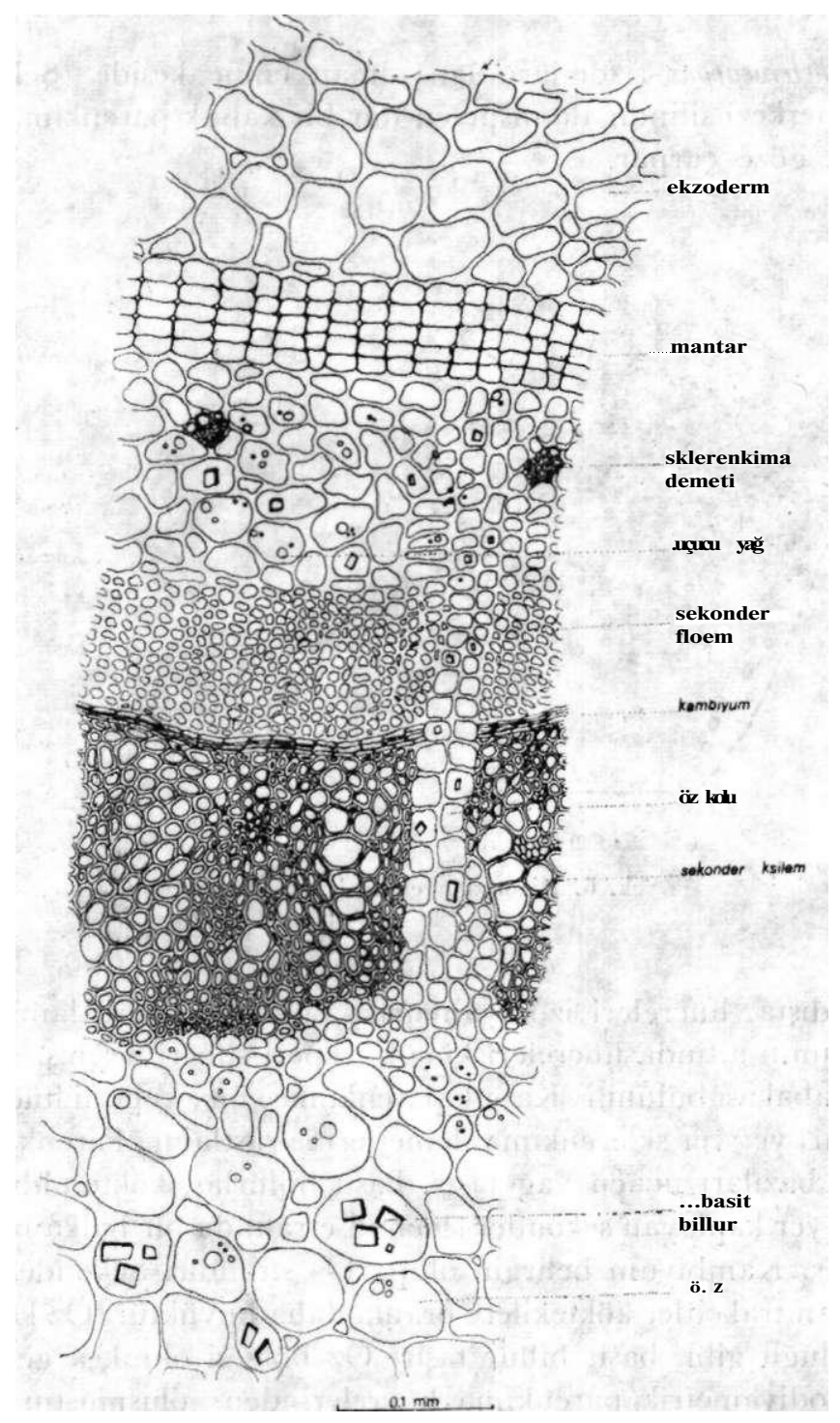

Şek. 7. Rizomdan enine kesi, anatomik 
Orthurus heterocarpus (Boiss.) Juz., memleketimizin güney Anadolu bölgesinde yaygın olarak rastlanan bir bitkidir.

O. heterocarpus ile G. urbanum morfolojik özelikleri ile birbirlerinden kolayca ayrılabilir. Ancak bu iki bitkinin parçalanmış ya da toz edilmiş kök ve rizomlarını, morfolojik özelikleriyle ayırmak olası değildir. Her iki bitkinin kök ve rizomları, dokuların çeşidi ve dizilişleri yönünden de biribirine çok benzemektedir; Fakat 0 . heterocarpus'tz. halka meydana getirmiş olan basit billurlara G. urbanum'da. rastlanmamaktadır. Bundan başka $G$. urbanum'da kabuk parenkima hücreleri çok miktarda nişasta içermekte, uçucu yağ damlaları mantarın hemen altındaki parenkima hücrelerinde ve özde, o. heterocarpus'a. oranla daha az bulunmaktadır. Böylece anatomik özeliklerden yararlanarak, her iki bitkinin toprakaltı kısımları birbirinden ayrilabilir.

\section{Ö Z E T}

Bu çalışmada, güney Anadoluda yaygın olarak bulunan ve halk arasında "karanfil", "karafil kökü" gibi isimlerle tanınan Orthurus heterocarpus (Boiss.) Juz. bitkisi ve toprakaltı kısımları morfolojik ve anatomik açıdan incelendi. Bitkinin morfolojik, kök ve rizomların anatomik özelikleri eczacılıkta drog olarak kullanılmış olan $G$. urbanum ile karşılaştırıldı.

Rosaceae familyasından olan bu bitki, bir çok botanikçi tarafından bir Geum türü olarak tanımlanmış $(1,2,6)$ ise de; stilusun düz, sepallerin petallerden uzun oluşu ve meyvanın daha az sayıda aken taşımasıyla Geum cinsinden kolaylıkla ayırdedilebilmektedir. Türkiye'de dört Geum türü (G. aleppicum Jacq., G. coccineum Sm., G. rivale L., G. urbanum L.) bulunduğu halde, en sık rastlanılanı ve Avrupa'da eskiden drog olarak kullanılmış olanı G. urbanum'dur.

o. heterocarpus bitkisi, G. urbanum'dan morfolojik yönden olduğu gibi, kök ve rizomlarının anatomik özelikleri bakımından da kolayca ayrılmaktadır. O. heterocarpus'un kök ve rizomlarında sekonder floemin etrafında halka şeklinde basit billur dizilerinin ve çok miktarda uçucu yağ damlalarının bulunmasına karşın G. urbanum'da bol miktarda nişastaya rastlanmaktadır. 
In this research, the underground parts of Orthurus heterocarpus (Boiss.) Juz. which is widespread in south part of Anatolia is known as "clove" or "root of clove" locally, were investigated. Morphological and histological details of 0 . heterocarpus and the underground parts are presented in this paper. Macroscopical and microscopical characteristics of the roots of 0 . heterocarpus are compared with that of $G$. urbanum which is used in pharmacy.

This plant which belongs to Rosaceae family has been accepted as a Geum species by many botanists $(1,2,6)$, on the other hand, having a flat stylus, sepals which are longer than petals and bearing fewer achenes in the fruit. The genus is easily distinguished from the genus Geum. Although there are four Geum species in Turkey (G. aleppicum Jacq., G. coccineum Sm. G. rivale L., G. urbanum L.) The most widespread and the one formerly used as a drug in Europe is $G$. urbanum.

O. heterocarpus is easily distinguished from G. urbanum both morphologically and by anatomical properties of the roots and the rhizomes. In the roots and rhizomes of 0 . heterocarpus, there are prismatic crystals in circular rows around the secondary floem and a large amount of volatile oil droplets, whereas a large amount of starch is present in G. urbanum.

\section{L İ T E R A T Ü R}

1. Boissier, E. - Flora Orientalis Vol. 2, Genevae et Basileae (1872).

2. Bolle, F., Fedde repert. spec, nov., 72, 1 (1933).

3. Davis, P. H . - Flora of Turkey and the East Aegean Islands, Vol. 4, University Press, Edinburgh (1972).

4. Esau, K. - Plant Anatomy, Second Edition, John Wiley and sons, Inc., New York (1965).

5. Garnier, G., Bezanger Beauquesne, L., Debraux, G. - Ressources Médicinales de la Flore Française Tome II, Vigot Frères Editeurs, Paris (1961).

6. Hegi, G. - Illustrierte Flora von Mittel-Europa Vol. 4, Carl Hanser Verlag, München (1906). 